Research Article

\title{
Pharmacological Potential of Anti-Inflammatory and Anti Nociceptive activity of bioactive fractions from Leaves of Maytenus emarginata
}

\author{
Sunil Kumar ${ }^{*}$, Mathew George, Lincy Joseph \\ Department of Pharmaceutical Sciences, Sharda University, Greater Noida-201306 U.P. India. \\ *Corresponding author's E-mail: sunilk8052@gmail.com
}

Received: 18-08-2021; Revised: 25-10-2021; Accepted: 04-11-2021; Published on: 15-11-2021.

\section{ABSTRACT}

The antinociceptive \& anti-inflammatory activities of extract were compared to dose of Phenylbutazone. The phytochemical secondary metabolites tested for include alkaloids, cardiac glycosides, flavonoids, phenols, saponins, steroids and terpenoids. Maytenus emarginata leaves extract demonstrated significant antinociceptive and anti- inflammatory effects in a dose-dependent manner. The extract dose at $200 \mathrm{mg} / \mathrm{kg}$ bw exhibited the highest antinociceptive and anti-inflammatory activities \& its activities were comparable to those of the respective reference drugs. BFLME (suspended in 1\% carboxy methyl cellulose) in doses of 50, 100 and $200 \mathrm{mg} / \mathrm{kg}$ caused a dose-dependent inhibition of swelling caused by carrageenin equivalent to $30.2-63.2 \%$ protection $(P<0.05-$ $P<0.001)$ and in cotton pellet granuloma, $47.2-45.4 \%$ protection $(P<0.01-P<0.001)$ was observed from inflammation. There was a significant increase in analgesiometer force induced pain in rat equivalent to $98.1-146.5 \%$ protection $(P<0.01-P<0.001)$ and $7.19-37.8$ $\%(P<0.05-P<0.001)$ protection against Acetic acid induced writhing. Phytochemical screening of the extract indicated the presence of alkaloids, cardiac glycosides, flavonoids, phenols, saponins, steroids and terpenoids. The present study therefore demonstrated the antinociceptive and anti-inflammatory properties of bioactive fraction of ethyl acetate extract from leaves of $M$. emarginata (BFLME), hence providing a basis for further research that may result in pure compounds that can be advanced into drug discovery.

Keywords: Inflammation, Nociceptive activity, Maytenus emarginata, Phytochemical Screening \& BFLME.

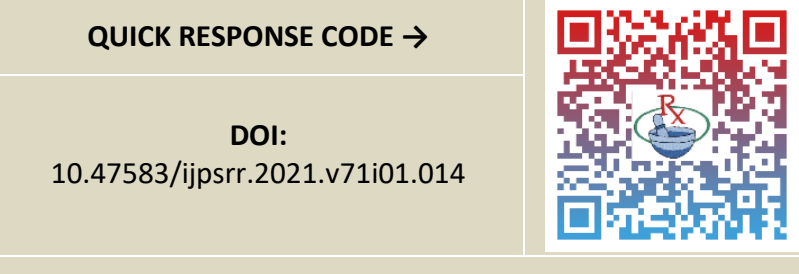

DOI link: http://dx.doi.org/10.47583/ijpsrr.2021.v71i01.014

\section{INTRODUCTION}

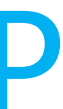
ain \& inflammation causes needless discomfort, suffering and lower efficiency of the victims. Predictable drugs for these conditions are expensive, not simply obtainable \& have adverse side effects. So, it needs to develop alternate therapeutic agents, such as medicinal plant derivatives, that are cheaper \& have less side effects. Maytenus emarginata is used in traditional medicine to treat pain and inflammation but there is no scientific evidence to confirm these ethnomedicinal claims. ${ }^{1}$

The present study tested for the anti-nociceptive and antiinflammatory properties of bioactive fraction of ethyl acetate extract from leaves of $M$. emarginata (BFLME). ${ }^{2}$ The plant samples sourced from Central Institute of Medicinal \& Aromatic Plant (CIMAP), Lucknow were dried and milled. Adult female Sprague Dawley rats weighing 130-170 gm were divided into five groups of 6 rats each scheduled for different treatments; positive controls and three experimental groups (50, 100 and $200 \mathrm{mg} / \mathrm{kg}$ bw extract). Pressure- induced pain, Acetic acid induced writhing, carrageenan-induced paw edema and cotton pellet induced granuloma were used to assess the antinociceptive and anti-inflammatory properties of the extract, respectively.

Due to harmless status of herbal medicine, they are in great demand in the developing as well as developed countries for primary and/or daily health care. Majority of Indian population have access to or practice various traditional medicines to maintain health or treat diseases. These include herbs that can be used either as monotherapy or as add-on therapy. But the most important challenge faced by these formulations arises due to lack of standardization, identification and pharmacopoeial standards (Ali, M., 2009). It is thus prudent to undertake the standardization of herbal medicine used in various healthcare systems. Moreover, herbal medicines are prepared from materials of natural origin which are prone to contamination, detoriation and variation in composition. There is a pressing need for evaluation and analysis of herbal drugs using sophisticated techniques. The plant Maytenus emarginata belonging to the family celastraceae, it is the evergreen tree that tolerates various types of pressures of the desert, locally known as "Kankero" in Hindi, "Thorny staff tree" in English. It grows through in India (Madhya Pradesh, Uttar Pradesh, Punjab, Maharashtra, Gujarat, Delhi, Bihar, Tamilnadu, and Rajasthan). Plants of this family generally grow as small trees, bushes or lianas and have resinous stems and leaves. They have been valued since antiquity because their extracts have useful medicinal properties. ${ }^{3}$

Various parts of this plant contain immense medicinal properties. Traditionally species of Maytenus used for 


\section{Test for Tannins and Phenolic Compounds}

\section{- $\quad \mathrm{FeCl} 3$ Test}

To 2-3 $\mathrm{ml}$ of each test solution, few drops of $5 \% \mathrm{FeCl} 3$ solution was added.

\section{- $\quad$ Lead acetate Test}

To each of the test solution of the extractives 2-3 ml of $10 \%$ lead acetate solution was added.

\section{Carbohydrate test}

\section{- Molisch Test}

Treat extract solution with few drops of alcoholic $\alpha$ napthol. Add $0.2 \mathrm{ml}$ of concentrated sulfuric acid slowly through the side of test tube, purple to violet color ring appears at junction.

\section{- Benedict's Test}

Treat extract solution with few drops of Benedict reagent (alkaline Solution containing cupric citrate complex) \& upon boiling on water bath, reddish brown ppt. Forms if reducing sugar is present.

\section{- Selwinoff's Test}

Hydrochloric acid reacts with ketose sugar to form derivative of furfuraldehyde, which give red colored compound when linked with resorcinol. Add extract solution to about $5 \mathrm{ml}$ of reagent and boil. Fructose gives red color with in half minute. The test is sensitive to $5.5 \mathrm{~m} . \mathrm{mol} /$ liter if glucose is absent; if glucose is present, it is less sensitive and in addition of large amount of glucose can give similar odor.

\section{- Caramelization}

Carbohydrate when treated with strong sulfuric acid, they undergo charring with the dehydration along with burning sugar smell.

\section{- Tollen's Test}

To $100 \mathrm{mg}$ of extract add $2 \mathrm{ml}$ of Tollen's reagent, a silver mirror is obtained inside the wall of the test tube, indicate the presence of aldose sugar.

\section{In-vitro antioxidant studies of different parts of Maytenus emarginata ${ }^{7}$}

\section{Total Flavonoid Content (TFC)}

Total flavonoid content of different parts of Maytenus emarginata were measured by colorimetric assay with some modification \& expressed as $\mathrm{mg}$ of quercetin equivalents $(\mathrm{QE}) / \mathrm{g}$ of extract. The crude extracts of each plant $(25 \mathrm{mg}$ ) were dissolved in $10 \mathrm{ml}$ of $50 \%$ methanol at room temperature. To $1 \mathrm{ml}$ aliquots of dissolved extracts or a standard solution of quercetin $(0-500 \mathrm{mg} / \mathrm{l}$, SigmaAldrich, St Louis, USA) was added to $4 \mathrm{ml}$ distilled water in a $10 \mathrm{ml}$ volumetric flask. At zero-time, $0.3 \mathrm{ml}$ of $5 \% \mathrm{NaNO}_{2}$, after $5 \mathrm{~min}, 0.3 \mathrm{ml} \mathrm{10 \%} \mathrm{AlCl}_{3}$ and at $6 \mathrm{~min}, 2 \mathrm{ml} 1 \mathrm{~N} \mathrm{NaOH}$ was added to the flask and immediately diluted with $2.4 \mathrm{ml}$ of distilled water. Absorbance of each mixture was determined at $510 \mathrm{~nm}$ against the blank.

\section{Total phenolic content (TPC)}

TPC was analyzed by the Folin-Ciocalteu colorimetric method using gallic acid as standard developed by Ragazzi and Veronese (1973) with modification and expressed as $\mathrm{mg} / \mathrm{g}$ gallic acid equivalent (GAE) on dry weight basis. The $25 \mathrm{mg}$ of different parts of Maytenus emarginata were dissolved in $10 \mathrm{ml}$ of $50 \% \mathrm{MeOH}: \mathrm{H}_{2} \mathrm{O}$ (1:1), at room temperature and in its $1.0 \mathrm{ml}, 1.0 \mathrm{ml}$ of Folin's Reagent $(1 \mathrm{~N})$ and $2.0 \mathrm{ml}$ of $\mathrm{Na}_{2} \mathrm{CO}_{3}(20 \%)$ were added subsequently. The test mixture was mixed properly on cyclomixer, left at room temperature for $30 \mathrm{~min}$ and maintained to $25 \mathrm{ml}$ with water. The absorbance of test mixture was measured at $725 \mathrm{~nm}$. The reported TPC were expressed as gallic acid equivalent (GAE) $\mathrm{mg} / \mathrm{g}$.

\section{DPPH (2,2-Diphenyl-1-Picryl- Hydroxyl Radical) radical scavenging activity}

The DPPH radical scavenging activity of different parts of Maytenus emarginata was determined by using the method proposed by Yen and Duh (1994). Different aliquot was added to $2.9 \mathrm{ml}$ of freshly prepared solution of DPPH ( $6 \times 10^{-5} \mathrm{M}$ in $\left.\mathrm{MeOH}\right)$. The absorbance was recorded at 517 $\mathrm{nm}$ at 0 time \& after 1 hour of incubation and inhibitory concentration $\left(\mathrm{IC}_{50}\right)$ were calculated as described by Kroyer (2004). IC 50 value is defined as the concentration of sample required to scavenge $50 \%$ of free radical. On the basis of their \% yield, TFC, TPC and DPPH, the leaves of Maytenus emarginata was selected for detailed pharmacological activity.

\section{Successive extraction from leaves of Maytenus emarginata}

The hydroalcoholic extract from leaves of Maytenus emarginata was dissolved in methanol: water (10:90) and fractionated successively with carbon tetra chloride, dichloromethane and ethyl acetate with the help of separating funnel for 4 times each, to obtain different fractions and hydro alcoholic portion. Their extractive values are given in Table 1.

Table 1: Extractive values of leaves of $M$. emarginata in solvent of different polarities

\begin{tabular}{|c|c|c|c|}
\hline S. No. & Solvent used for Fractionation & Polarity index & Extractive value (\% w/w) \\
\hline 1. & Carbon tetra chloride & 1.6 & 6.3 \\
\hline 2. & Dichloromethane & 3.1 & 13.35 \\
\hline 3. & Ethyl acetate & 4.4 & 23.92 \\
\hline 4. & Hydro alcoholic & $(5.1: 9.0)$ & 58.92 \\
\hline
\end{tabular}




\section{Chromatographic analysis}

Each extract obtained from the leaves of $M$. emarginata were standardized with quercetin (a marker flavonoid) to identify the flavonoid rich extract. Standardization of each extract obtained from the leaves of $M$. emarginata reviled that ethyl extract portion having quercetin. Thus, Ethyl acetate extract $(25 \mathrm{gm})$ of $M$. emarginata was chromatographed over a silica gel column to obtain purified fractions ( $F r$.) with different solvents based on their polarity. The solvents were Benzene, ethyl acetate and methanol, with polarity index $2.7,4.4$ and 5.1 respectively. The elution was done according to the respective dilution along with co-TLC analysis with marker flavonoid (quercetin; SD Fine-Chem Ltd, Mumbai) on precoated silica gel plate (Merck $60 \mathrm{~F}_{254}$ ) as stationary phase and ethyl ether: ethyl acetate: formic acid (6:4:1 v/v) as mobile phase. The plates were visualized under UV 254 $\mathrm{nm}, 366 \mathrm{~nm}$ and visible. If required spray the plate with anisaldehyde -sulfuric acid reagent $0.5 \mathrm{ml}$ Anisaldehyde $+10 \mathrm{ml}$ glacial acetic acid $+85 \mathrm{ml}$ methanol $+5 \mathrm{ml}$ conc. $\mathrm{H}_{2} \mathrm{SO}_{4}$ ) and heat at $110^{\circ} \mathrm{C}$ for $10 \mathrm{~min}$. The standardized flavonoid fractions obtained after column chromatography was mixed together, evaporate and concentrate. These obtained residues were termed as bioactive fraction from leaves of $M$. emarginata (BFLME) and used for pharmacological evaluation.

\section{Pharmacological studies}

\section{Acute Toxicity Study of leaves of Maytenus emarginata ${ }^{8}$}

Acute Toxicity studies were performed according to the OECD (Organization for Economic Co-operation and Development) guidelines no. 425 following the procedure of Up and Down. In this procedure hydroalcoholic extract of leaves of $M$. emarginata in $0.1 \%(\mathrm{w} / \mathrm{v})$ aqueous suspension of sodium carboxy methyl cellulose (CMC) was administered orally to female Sprague Dawley rats weighing 130-170 gm. The hydroalcoholic extract of leaves at doses of 50,100 and $200 \mathrm{mg} / \mathrm{kg} \mathrm{b.w}$ by oral gavage were given to different groups. The animals were allowed free access to water and food. However, all the animals were deprived of food for $2 \mathrm{~h}$ before and $4 \mathrm{~h}$ after dosing. The animals were continuously monitored during first $4 \mathrm{~h}$ and every one hour during the first $12 \mathrm{~h}$ for any adverse effects. Later they were monitored (daily, twice) for any abnormal changes throughout the study period (14 days). In addition, the body weight and food consumption of each animal were measured once per week.

\section{Animals and Drug Treatment}

The adult Sprague Dawley rats of the either sex weight about 140-180 gm were fasted for $48 \mathrm{hr}$ with free access to water \& libutum, divided into six experimental groups. They were placed in cages with grating floor to avoid coprophagy. BFLME (suspended in 1\% carboxy methyl cellulose) at dose of 50,100, $200 \mathrm{mg} / \mathrm{Kg}$ body wt., p.o were administered once daily for three consecutive days. Phenylbutazone (100 mg/Kg; p.o) was used as the standard anti-inflammatory and anti- nociceptive. Control group of animals $(n=6)$ received suspension of $1 \%$ CMC in distilled water $(10 \mathrm{ml} / \mathrm{Kg})$. Experiments were conducted on day 3 , 60 minutes for anti- inflammatory and 30 minutes for antinociceptive.

\section{Anti-Inflammatory Activity}

\section{$\lambda$ Carrageenin-induced paw oedema}

Rats were injected with $0.1 \mathrm{ml}$ of $1 \% \lambda$ carrageenin into the sub-planter side of the left hind paw (Winter et al., 1962). The paw was marked with ink at the level of lateral malleolus and dipped in Perspex cell up to this mark. Paw volume was measured immediately with an Ugo Basile Plethysmometer and $3 \mathrm{hrs}$ after injecting the $\lambda$ carrageenin suspension. The BFLME extract and phenylbutazone was administered orally by gavage, $1 \mathrm{hr}$ before the $\lambda$ carrageenin injection. ${ }^{9}$ Significant reduction in the paw volume compared to vehicle treated control animals were considered as anti-inflammatory response. \% Inhibition of oedema was calculated as follows:

$\%$ Inhibition $=\left(1-V_{T} / V_{C}\right) \times 100$

$\mathrm{V}_{\mathrm{T}}=\mathrm{Paw}$ volume in drug treated rats.

$\mathrm{V}_{\mathrm{C}}=$ Paw volume in control group of rats.

\section{Cotton pellet induced granuloma}

Rats were anesthetized with ether and incision was made on the lumber region (Winter et al., 1957). By a blunted forceps subcutaneous tunnel was formed \& cotton (100 $\mathrm{mg} \pm 1 \mathrm{mg}$ ) was inserted in the groin area. Experimental groups of 6 animals received either test drug $(50,100,200$ $\mathrm{mg} / \mathrm{Kg}$ body wt., p.o.) or reference drug $(100 \mathrm{mg} / \mathrm{kg}$ body wt.) for seven consecutive days from day of cotton pellet insertion. ${ }^{10}$ The animals were sacrificed and the pellets were removed \& dried until the weight remained constant on $8^{\text {th }}$ day according to the procedure described and the net dry weight was calculated.

\section{Antinociceptive activity ${ }^{11}$}

\section{Analgesiometer induced pain}

Analgesic effect of BFLME test in rat of either sex, using the Ugo Basile Analgesiometer (Rodriguez et al., 1990). This method involves application of the force to the paw of rat using analgesiometer, which exert force that increase at constant rate. Rat was gently placed between plinth \& plunger. Instrument was switched on and a constant motor rate used to drive the plunge on to paw of the mice. When mice struggle, the instrument was switched off and the force at which animal felt pain was read on a scale calibrated in grams $x 10$ by a pointer. The pre and the posttreatment weight causing pain were determined for each mouse. The doses of test drug or reference drug were administered 60 minutes before testing.

\section{Acetic acid induced writhing}

Animals received BFLME extract $(50,100,200 \mathrm{mg} / \mathrm{kg})$ \& standard drug orally 30 minutes before injection of the $0.6 \%$ acetic acid $(10 \mathrm{ml} / \mathrm{kg}$, i.p). The number of abdominal 
contractions (writhing) \& stretching with a jerk of the hind limb were counted for 15 minutes after administering acetic acid and \% inhibition was calculated.

\section{Statistical Analysis}

The data were analyzed by using Prism Pad software for determining the statistical significance between different groups. The observation in various groups were expressed as mean \pm SEM and analyzed by using one way ANOVA with Newman-Keuls Multiple Comparison method. The value of $P<0.05$ to $P<0.001$ were considered to be significant, when compared with ulcer control group.

\section{RESULTS}

\section{In-vitro antioxidant studies of different parts of $M$. emarginata}

\section{Total Flavonoid Content (TFC)}

Flavonoid Content present of different parts of $M$. emarginata was expressed in terms of Gallic acid and was found to be $32.80 \pm 0.50,13.20 \pm 0.80,28.30 \pm 0.30$, and $14.24 \pm 0.20 \mathrm{mg} \mathrm{GAE} / \mathrm{g}$ dry weight of the leaf, flower, bark and root respectively (Table 3 ).

\section{Total phenolic content (TPC)}

Phenolic content present of different parts of $M$. emarginata was expressed in terms of Gallic acid and was found to be $4.3 \pm 0.16,1.3 \pm 0.22,3.3 \pm 0.50$, and $3.4 \pm 0.42$ $\mathrm{mg}$ GAE/g dry weight of the leaf, flower, bark and root respectively (Table 4).

Table 2: Qualitative phytochemical screening of crude extracts of selected plant's part

\begin{tabular}{|c|c|c|c|c|c|c|}
\hline \multirow{2}{*}{ S. No. } & \multirow{2}{*}{ Phytoconstituents } & \multirow{2}{*}{ Tests } & \multicolumn{4}{|c|}{ Crude extract of different parts $B$. aristata } \\
\hline & & & Leaf & Flower & Bark & Root \\
\hline \multirow{3}{*}{1} & \multirow{3}{*}{ Alkaloids } & Dragendroff's Test & + & + & + & + \\
\hline & & Mayer's Test & + & + & + & + \\
\hline & & Hager's Test & + & + & + & + \\
\hline 2 & Flavonoids & Shinoda Test & + & + & + & \\
\hline \multirow[b]{2}{*}{3} & \multirow[b]{2}{*}{ Proteins \& Amino acid } & Million's Test & + & + & - & - \\
\hline & & Ninhydrin Test & + & + & - & + \\
\hline \multirow[b]{4}{*}{4} & \multirow{4}{*}{ Test for Tannins } & Gelatin Test & + & + & - & + \\
\hline & & Ferric chloride Test & + & - & - & - \\
\hline & & Vanillin hydrochloride Test & + & - & - & - \\
\hline & & Alkaline reagent Test & + & - & - & - \\
\hline \multirow[b]{2}{*}{5} & \multirow{2}{*}{$\begin{array}{l}\text { Test for Sterol \& } \\
\text { Triterpenoids }\end{array}$} & \multirow{2}{*}{ Liebermann- Burchard Test } & + & + & - & - \\
\hline & & & + & + & + & + \\
\hline \multirow[b]{2}{*}{6} & \multirow{2}{*}{$\begin{array}{l}\text { Test for free sugar Saponins } \\
\text { Glycoside }\end{array}$} & Raymond's Test & + & + & + & \\
\hline & & Legal test & + & + & + & + \\
\hline 7 & Test for Fats and Oils & & + & + & + & + \\
\hline \multirow[b]{2}{*}{8} & \multirow{2}{*}{$\begin{array}{l}\text { Test for Tannins and Phenolic } \\
\text { Compounds }\end{array}$} & $\mathrm{FeCl} 3$ Test & + & + & - & + \\
\hline & & Lead acetate Test & + & + & - & + \\
\hline \multirow{3}{*}{9} & \multirow{3}{*}{$\begin{array}{l}\text { Test for } \\
\text { Carbohydrate }\end{array}$} & Molisch's Test & + & + & + & + \\
\hline & & Barfoed's Test & + & + & + & + \\
\hline & & lodine Test & + & + & + & + \\
\hline
\end{tabular}

Where, $(+)=$ Presence $(-)=$ Absence

Table 3: Total Phenolic content present in different parts of $M$. emarginata

\begin{tabular}{|c|c|c|}
\hline S. No. & Part of the plant & TFC (GA equivalent in $\mathbf{~ m g / g}$ ) \\
\hline 1. & Leaf & $35.80 \pm 0.50$ \\
\hline 2. & Flower & $16.20 \pm 0.80$ \\
\hline 3. & Bark & $31.30 \pm 0.30$ \\
\hline 4. & Root & $17.24 \pm 0.20$ \\
\hline
\end{tabular}

* All values are average of three determinations, mean \pm SEM 
Table 4: Total Phenolic content present of different parts of M. emarginata

\begin{tabular}{|c|c|c|} 
S. No. & Part of the plant & $\begin{array}{c}\text { Phenolic Content } \\
\text { (Gallic acid mg /g*) }\end{array}$ \\
\hline 1 & Leaf & $5.2 \pm 0.16$ \\
\hline 2 & Flower & $2.1 \pm 0.22$ \\
\hline 3 & Bark & $4.2 \pm 0.50$ \\
\hline 4 & Root & $4.3 \pm 0.42$ \\
\hline
\end{tabular}

* All values are average of three determinations, mean \pm SEM

Table 5: Free radical scavenging activity, expressed as percent inhibition in terms of DPPH (2,2-Diphenyl-1-PicrylHydroxyl Radical) radical scavenging of different parts of M. emarginata

\begin{tabular}{|c|c|c|c|}
\hline S. No. & Sample & $\left(\mathbf{I} \mathbf{C}_{\mathbf{5 0}} \boldsymbol{\mu g} / \mathbf{m l}\right)$ & ARP \\
\hline 1. & Leaf & $312.13 \pm 3.21$ & 0.21 \\
\hline 2. & Flower & $954.23 \pm 8.54$ & 0.01 \\
\hline 3. & Bark & $497.51 \pm 6.12$ & 0.14 \\
\hline 4. & Root & $1103.23 \pm 6.14$ & 0.08 \\
\hline
\end{tabular}

All presented values were calculated from three experiment repetitions

On the basis of their \% yield, TFC, TPC and DPPH, the leaves of Maytenus emarginata was selected for detailed pharmacological activity.

\section{Successive extraction and Chromatographic analysis}

The successive extraction from leaves of $M$. emarginata in different solvent based on their polarities were carbon tetra chloride $(6.3 \% \mathrm{w} / \mathrm{w})$, dichloromethane (13.35\% $\mathrm{w} / \mathrm{w})$, ethyl acetate $(23.92 \% \mathrm{w} / \mathrm{w})$ and hydro alcoholic (58.92 \% w/w). In chromatographic analysis each extract obtained from the leaves of $M$. emarginata was standardized with quercetin (a marker flavonoid) to identify the flavonoid rich extract. Results of this study have shown that ethyl acetate extract was rich in quercetin (Table 6). Therefore, the standardized flavonoid fractions obtained after column chromatography was mixed together, evaporate and concentrate. These obtained residues were termed as bioactive fraction of leaves of $M$. emarginata (BFLME) and used for pharmacological evaluation.

Table 6: TLC Profile of from Ethyl Acetate fraction standardized quercetin

\begin{tabular}{|c|c|}
\hline Solvent system: & $\begin{array}{c}\text { ethyl ether: ethyl acetate: formic } \\
\text { acid }(6: 4: 1 \mathrm{v} / \mathrm{v})\end{array}$ \\
\hline Visualizing Agent & $\begin{array}{c}\text { Anisaldehyde sulphuric acid } \\
\text { reagent }\end{array}$ \\
\hline Rf values (Reference): & $\begin{array}{c}R f \\
0.96 \text { (quercetin) }\end{array}$ \\
\hline Rf values (Bioactive fraction) & In the general TLC profile \\
& developed 8 bands at \\
& $0.04,0.06,0.23,0.27,0.35$ \\
& $0.54,0.73$ and 0.96. \\
\hline
\end{tabular}

\section{Pharmacological studies}

\section{Acute Toxicity Studies}

The results of the above observation indicated that there were no abnormalities found in all groups. The given test drug at the doses of 400, 800 and $2000 \mathrm{mg} / \mathrm{kg} \mathrm{b.w}$ was found to be safe. Accordingly, the acute oral LD50 of the extractives was concluded to exceed $2000 \mathrm{mg} / \mathrm{kg} \mathrm{b.w}$, the highest dose tested in the study (Table 7). There were no changes in nature of stool, urine and eye color of all the animals. In addition, the body weight and food consumption of each animal were measured once per week (Table 8).

Table 7: Mortality observation of hydroalcoholic extract of leaves of $M$. emarginata in each tested group

\begin{tabular}{|c|c|c|c|c|}
\hline Plant parts & \multicolumn{4}{|c|}{ Hydroalcoholic extract of leaves of M. emarginata } \\
\hline Group & 1 & 2 & 3 & 3 \\
\hline Dose $(\mathbf{m g} / \mathbf{k g}$ b.w) & 400 & 800 & 2000 & 2000 \\
\hline No. of animals dead & $\mathrm{Nil}$ & $\mathrm{Nil}$ & $\mathrm{Nil}$ & $\mathrm{Nil}$ \\
\hline
\end{tabular}

Table 8: Effect of Body weight and food intake after single administration of hydroalcoholic extract of leaves (Acute Study)

\begin{tabular}{|c|c|c|c|c|c|c|c|}
\hline \multirow{2}{*}{ Period } & \multicolumn{2}{|c|}{ Group I } & \multicolumn{2}{c|}{ Group II } & \multicolumn{2}{c|}{ Group III } \\
\cline { 2 - 8 } & Body weight (g) & Food Intake (g) & Body weight (g) & Food Intake (g) & Body weight (g) & Food Intake (g) \\
\hline \multirow{2}{*}{ Initial } & $145.2 \pm$ & $10.5 \pm$ & $164.20 \pm$ & $14.5 \pm$ & $164.02 \pm$ & $10.23 \pm$ \\
\hline \multirow{2}{*}{ First week } & 21.41 & 1.54 & 18.21 & 3.21 & 21.36 & 2.14 \\
\hline Second & $159.5 \pm$ & $10.5 \pm$ & $153.86 \pm$ & $16.32 \pm$ & $163.04 \pm$ & $12.54 \pm$ \\
week & 18.21 & 2.01 & 22.46 & 2.54 & 15.63 & 2.50 \\
\hline
\end{tabular}

Values are expressed as mean \pm SEM $(n=3)$, The difference in \% increase of body weight and food intake of different groups 1,2 and 3 treated with hydroalcoholic extract of leaves of M. emarginata was insignificant at the end of study (14 days). 


\section{Anti-Inflammatory Activity}

\section{$\lambda$ Carrageenin-induced paw oedema}

The BFLME at the dose level of 50, 100 and $200 \mathrm{mg} / \mathrm{kg} \mathrm{b.w}$ produced a dose- dependent inhibition of swelling caused by the $\lambda$ Carrageenin at $3 \mathrm{hrs}$ equivalent to $30.2-63.2 \%$ $(P<0.05-P<0.001)$ protection (Table 9$)$.

\section{Cotton pellet induced granuloma formation}

BFLME at a dose level of 50, 100 and $200 \mathrm{mg} / \mathrm{kg} \mathrm{b.w}$ significantly decreased the granuloma weight from $47.2-$ 45.4\% $\quad(P<0.01-P<0.001)$ respectively compared to reference compound phenyl butazone $34.6 \% \quad(P<0.001)$ (Table 10).

Table 9: Effect of BFLME on $\lambda$ Carrageenin-induced paw oedema in rats

\begin{tabular}{|c|c|c|c|}
\hline Treatment & Dose $(\mathbf{m g} / \mathbf{k g} b . w)$ & \multicolumn{2}{|c|}{ Paw volume $(\mathbf{m l})$ at $\mathbf{3}$ hrs } \\
\% Inhibition
\end{tabular}

*Values are mean \pm SEM for six rats, ${ }^{*} P<0.05$ compared to control group, ${ }^{* *} P<0.01$ compared to control group and ${ }^{* * *} P<$ 0.001 compared to control group.

Table 10: Effect of BFLME on cotton pellet-induced granuloma in rats

\begin{tabular}{|c|c|c|}
\hline Treatment & Dose $(\mathbf{m g} / \mathbf{k g}$ b.w) & Dry weight $(\mathbf{m g})$ \\
\hline Control & ----- & $47.5 \pm 2.7$ \\
\hline BFLME & 50 & $45.2 \pm 0.70^{*}$ \\
\hline BFLME & 100 & $36.7 \pm 0.81^{* *}$ \\
\hline BFLME & 200 & $33.4 \pm 0.51^{* *}$ \\
\hline Phenylbutazone & 100 & $32.6 \pm 0.34^{* *}$ \\
\hline
\end{tabular}

*Values are mean \pm SEM for six rats, ${ }^{*} P<0.01$ compared to control group and ${ }^{* *} P<0.001$ compared to control group.

\section{Anti-Nociceptive activity}

\section{Analgesiometer induced pain}

The BFLME at a dose level of 50, 100 and $200 \mathrm{mg} / \mathrm{kg} \mathrm{b.w}$ caused a significant increase in the analgesiometer induced force $(P<0.01$ to $P<0.001)$ and exhibited resistance against pain after 30 min equivalent to $98.1-$ $146.5 \%$ protection respectively (Table 11 ).

Table 11: Effect BFLME on force induced pain in rats

\begin{tabular}{|c|c|c|c|}
\hline \multirow{2}{*}{ Treatment } & Dose $\mathbf{( m g / k g} \boldsymbol{b} . \boldsymbol{w})$ & \multicolumn{2}{|c|}{ Weight causing pain $\mathbf{( g )}$} \\
\hline Control & -- & $86.1 \pm 2.2$ & $85.81 \pm 3.29$ \\
\hline BFLME & 50 & $85.9 \pm 1.3$ & $98.1 \pm 4.08^{*}$ \\
\hline BFLME & 100 & $84.1 \pm 1.6$ & $123.4 \pm 3.1^{* *}$ \\
\hline BFLME & 200 & $86.3 \pm 1.6$ & $146.5 \pm 3.1^{* *}$ \\
\hline Phenylbutazone & 100 & $84.2 \pm 2.29$ & $155.5 \pm 6.5^{* *}$ \\
\hline
\end{tabular}

*Values are mean \pm SEM for six rats, ${ }^{*} P>0.05$ compared to control group and ${ }^{* *} P<0.001$ compared to control group.

\section{Acetic acid induced writhing}

The BFLME at the dose level of 50, 100 and $200 \mathrm{mg} / \mathrm{kg} \mathrm{b.w}$ in stretching episodes induced by acetic acid $(0.6 \%)$ are summarized in Table 12 . The BFLME showed significant reduction in abdominal cramping and percentage inhibition of abdominal cramping was from 7.19-37.8 \% $(P<0.05-P<0.001)$ The BFLME at the dose of $50 \mathrm{mg} / \mathrm{kg} \mathrm{b.w}$ was insignificant statistically. 
Table 12: Effect of BFLME on acetic acid induced pain in rats

\begin{tabular}{|c|c|c|c|}
\hline Treatment & Dose $(\mathbf{m g} / \mathbf{k g} \boldsymbol{b} . \boldsymbol{w})$ & No. of writhing & \% Inhibition \\
\hline Control & ---- & $26.4 \pm 1.4$ & --- \\
\hline BFLME & 50 & $24.5 \pm 0.18^{*}$ & 7.19 \\
\hline BFLME & 100 & $19.4 \pm 0.80^{* *}$ & 26.5 \\
\hline BFLME & 200 & $16.4 \pm 0.45^{* *}$ & 37.8 \\
\hline Phenylbutazone & 100 & $16.8 \pm 0.27^{* *}$ & 36.3 \\
\hline
\end{tabular}

*Values are mean \pm SEM for six rats, ${ }^{*} P<0.05$ compared to control group and ${ }^{* *} P<0.001$ compared to control group.

\section{CONCLUSION}

As fresh plant materials (samples) were collected and foreign matter was discarded before the preparation of the sample hence it may be considered as no foreign organic matter was present in the samples. Moisture content is important parameter of physiochemical analysis. Low moisture content reduces errors in the estimation of the actual weight of drug material, reduces components hydrolysis by reducing the activities of hydrolytic enzymes which may destroy the active components, and also reduces the proliferation of microbial colonies and therefore minimize the chance of spoilage due to microbial attack (Shellard, 1958).The obtained data in this study discovered significant antiinflammatory and antinociceptive properties of bioactive fraction from leaves of $M$. emarginata (BFLME) which due to presence of the bioactive ingredients with the pharmacological potential. Extract verified a dose dependent response to carrageenan-induced inflammation, cotton pellet induced granuloma, analgesiometer induced pain \& acetic acid induced writhing.

The dose at $200 \mathrm{mg} / \mathrm{kg} \mathrm{b.w}$, the extract exhibited the highest anti- inflammatory \& antinociceptive activities. The anti-inflammatory and antinociceptive activities of the extract at dose of $200 \mathrm{mg} / \mathrm{kg}$ b.w was comparable to antiinflammatory and antinociceptive activities of the respective reference drugs.

In this study the result suggests that administration of BFLME showed inhibition of inflammation \& pain in the experimental animals. Further studies are in progress to find out the exact mechanism of action \& responsible active constituents for anti-inflammatory and antinociceptive activity.

\section{REFERENCES}

1. Clarice C. V. Pharmacological potential of Maytenus species and isolated constituents, especially tingenone, for treatment of painful inflammatory diseases. 2017; 4: 533540.

2. Shih Chieh-Chih, Hwang Hwong-Ru. Anti-Inflammatory and Antinociceptive Effects of Ethyl Acetate Fraction of an Edible Red Macroalgae. 2018; 11: 24-37.

3. Kumawat K. Bhupendra, Rathore S. Devendra, Gupta k. Mahesh. Microscopical evaluation of leaf of Maytenus emarginata. 2016; 1: 7-18.

4. Sagwan Savita. Maytenus emarginata (Willd.): A Promising Drug for Cancer Therapy. 2011; 3: 22-35.

5. Joshi U. Prabhakar, \& Wagh R. Dayaram. GC-MS Analysis of Phytochemical Compounds Present in The Stembark Extracts of Plant Maytenus emarginata. 2019; 2: 159.

6. Chukwuma S. Ezeonu \& Chigozie M. Ejikeme. Qualitative and Quantitative Determination of Phytochemical Contents of Indigenous Nigerian Softwoods. 2016; 1: 16-23.

7. Khan Muqtar, \& Khan M. A. Hepatoprotective activity of Maytenus emarginata against paracetamol induced liver injury in male wistar rats. 2014; 6: 320-323.

8. Morris J. Christopher. Carrageenan-Induced Paw Edema in the Rat and Mouse: Methods in Molecular Biology. 2013; 2: 225-115.

9. Afsar S.K. Assessment of anti-inflammatory activity of Artemisia vulgaris leaves by cotton pellet granuloma method in Wistar albino rats. 2013; 1: 27-36.

10. Chandel S. Saket \& Patel K. Pushpendra. A Detailed Review on Nociceptive Models for the Screening of Analgesic Activity in Experimental Animals. 2016; 2: 44-50.

Source of Support: The author(s) received no financial support for the research, authorship, and/or publication of this article.

Conflict of Interest: The author(s) declared no potential conflicts of interest with respect to the research, authorship, and/or publication of this article.

For any question relates to this article, please reach us at: editor@globalresearchonline.net New manuscripts for publication can be submitted at: submit@globalresearchonline.net and submit_ijpsrr@rediffmail.com 